\title{
DRIVERS OF BURNED AREA PATTERNS IN CERRADO: THE CASE OF MATOPIBA REGION
}

\author{
P.S.Silva ${ }^{1 *}$, J.A.Rodrigues ${ }^{2}$, F.L.M.Santos ${ }^{2}$, A.A.Pereira ${ }^{3}$, J. Nogueira ${ }^{2}$, C.C. DaCamara ${ }^{1}$, R. Libonati ${ }^{2,1}$ \\ ${ }^{1}$ Instituto Dom Luiz (IDL), Faculdade de Ciências, Universidade de Lisboa, Campo Grande, 1749-016, Lisboa, Portugal - \\ (pssilva, cdcamara)@fc.ul.pt \\ ${ }^{2}$ Departamento de Meteorologia, Instituto de Geociências, Universidade Federal do Rio de Janeiro, 21941-916, Rio de Janeiro, \\ Brazil - abrant.julia@gmail.com, filmaias@hotmail.com,joananog@yahoo.com.br, renata.libonati@igeo.ufrj.br \\ ${ }^{3}$ Instituto Federal de Ciência e Tecnologia do Sul de Minas Gerais, 37890-000, Muzambinho, MG, Brazil - \\ allan.pereira@ifsuldeminas.edu.br
}

KEY WORDS: Brazilian savanna, remote sensing, land use, climate, reanalysis, agricultural frontier, microregion

\begin{abstract}
:
The Brazilian savanna (Cerrado) is one of the most important biodiversity hotspots in the world. Being a fire-dependent biome, its structure and vegetation dynamics are shaped by and rely on the natural occurring fire regime. Over the last decades, Cerrado has been increasingly threatened by accelerated land cover changes, namely the uncontrolled and intense use of fire for land expansion. This is particularly seen in Brazil's new agricultural frontier in northeastern Cerrado: the MATOPIBA region. Changes in MATOPIBA's fire regime resulting from this rapid expansion are still poorly understood. Here we use satellite-derived datasets to analyze burned area patterns in MATOPIBA over the last 18 years, at the microregions level. We further evaluate the role of climate and land use in spatial and temporal burned area variability and assess their trends in the last two decades. Results show an increased contribution of MATOPIBA to Cerrado's total burned area over the last few years: Maranhão and Tocantins present the highest values of total burned area with some microregions burning more than twice its area over the study period. Climate is shown to play a relevant role in MATOPIBA's fire activity, explaining $52 \%$ of the interannual variance, whereas land use and burned area were found to have more complex interactions that are highly dependent on the regional context. Lastly, climate and land use drivers are found to have an overall increasing trend over the last two decades, whereas burned area trends show much heterogeneity within MATOPIBA.
\end{abstract}

\section{INTRODUCTION}

Fire events are complex disturbances that influence vegetation dynamics, biodiversity and ecosystem services, particularly in fire-dependent biomes such as Brazilian savannas (Cerrado) (Hardesty et al., 2005). Cerrado is one of the most important global biodiversity hotspots and is increasingly threatened partly due to a lack of a consistent fire policy (Durigan, Ratter, 2016). This fire-prone biome relies on fire to shape its vegetation distribution and composition and burns regularly constrained to the annual and seasonal climatological conditions. Nevertheless, changes in the fire regime consequent of future aggravation of climate conditions might lead to irreversible damage.

While climate has been shown to strongly influence fire activity in Cerrado (Silva et al., 2019; Hoffmann et al., 2012), anthropogenic action plays a preponderant role: over the last decades, most human-induced ignitions have been found to be due to increases in land use management, expansion for livestock and agriculture (Song et al., 2018). The uncontrolled and intense use of fire has contributed to accelerate land cover changes (Lapola et al., 2014) and to disrupt natural spatial patterns of fire events in this biome. The role of human activity is particularly relevant in Brazil's new agricultural frontier, the northern region of Cerrado known as MATOPIBA (Miranda et al., 2014).

Satellite-derived datasets have proven a useful tool to understand changes in the fire regimes, particularly in Brazil where field records are costly and irregular. These datasets provide long-term burned area information with reasonable spatial resolution, improved accuracy, higher spatial coverage and temporal homogeneity. They allow a comprehensive characterization of systematic spatial and temporal burned area patterns, improving the understanding of fire activity in Cerrado (Rodrigues et al., 2019; Nogueira et al., 2017; Libonati et al., 2015).

Here, we explored the burned area patterns in Cerrado over the last 18 years, in the context of regional climate variations and anthropogenic drivers. Land use and a purely climate-driven fire danger index are evaluated as drivers of spatial burned area patterns. We focused on the MATOPIBA region, given its importance as the new agricultural frontier, and perform our study at the microregions level, as defined by the Brazilian Institute of Statistics and Geography (IBGE). Understanding regional fire regimes can provide useful information to trigger appropriate fire management and policy decisions.

\section{METHODOLOGY}

\subsection{Study Area}

Our study area is the MATOPIBA region, considered here the IBGE's microregions that compose the Maranhão (MA), Tocantins (TO), Piaui (PI) and Bahia (BA) states that are included in the geographical extension of Cerrado. IBGE's microregions are groups of municipalities with common geographical characteristics (IBGE, 1990). In our analysis, MATOPIBA contains 41 microregions in a $0.25^{\circ}$ regular grid by nearest-neighbor interpolation, totalizing $709508 \mathrm{~km}^{2}$ of extension (Figure 1), which represents $35 \%$ of Cerrado biome.

Although the agricultural frontier in MATOPIBA exists since the 80 's, it solely began to rapidly expand after the agri-food crisis of 2007/2008 (Pereira, Pauli, 2016). This region is highly sought by businesses given the cheap labor, inefficient supervision and 
arable land. The main cultures are corn, soybean, and cotton (Sano et al., 2010).

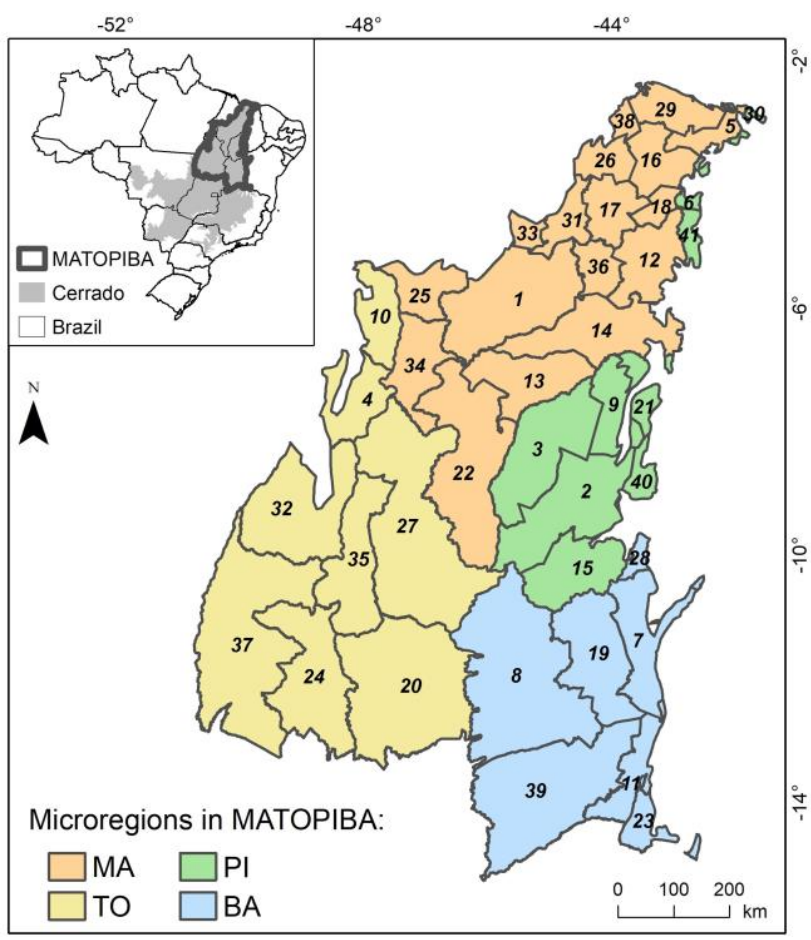

Figure 1. Spatial distribution of the 41 microregions from MATOPIBA in the Cerrado biome.

\subsection{MCD64 satellite burned area (SBA) product}

We used the MCD64A1 BA version (collection 6, C6) product (Giglio et al., 2018) derived from MODIS sensors developed by the National Atmospheric Space Agency (NASA). The algorithm of the C6 is based on multiple stages, using time series composites and conditional thresholds (Giglio et al., 2018) to estimate the monthly SBA at $500 \mathrm{~m}$ of spatial resolution from 2000 to present. The adjacent non-overlapping tiles of 10 degrees square (at the equator) for the study area were downloaded in HDF4 file format. Tiles of the Burn Date layers were mosaicked and remapped using the Modis Reprojection Tool from NASA (Dwyer, Schmidt, 2006). This product was already validated in the Cerrado biome and has been shown to accurately identify burned areas, particularly in northern Cerrado (Rodrigues et al., 2019).

\subsection{Datasets of drivers on SBA patterns}

As anthropogenic drivers, we evaluated land use (LU) and climate (CL) effects. LU was evaluated using Mapbiomas v.3.1 (Mapbiomas Project, 2019), a dataset developed by a collaborative network of experts in Brazilian biomes. Mapbiomas uses a machine learning method (Random Forest) to perform a pixel by pixel classification based on an annual mosaic from Landsat satellite images at $30 \mathrm{~m}$ spatial resolution with a median value in each year. The training of this algorithm uses balanced samples and in post-classificatory images, temporal, spatial, frequency and gap filling filters are applied (Mapbiomas Project, 2019). LU is divided in six classes (Farming, Pasture, Agriculture, Annual and Perennial Crop, Semi-Perennial Crop and Mosaic of Agriculture and Pasture), and data was downloaded in GeoTIFF format and stored in WGS84 datum from 2001 to 2017.
To account for the effects of CL, we used the Canadian Forest Fire Weather Index (FWI) System (Van Wagner, 1987). The FWI system consists of six components that account for the effects of fuel moisture and wind on fire behavior and has been shown to be highly adaptable and accurately replicate fire danger conditions in diverse ecosystems around the world (Pinto et al., 2018; Taylor, Alexander, 2006). The first three FWI components are fuel moisture codes: the Fine Fuel Moisture Code (FFMC), the Duff Moisture Code (DMC), and the Drought Code (DC). High values indicate dry fuels and only DC has memory. The remaining three components are: the Initial Spread Index (ISI), the Build-up Index (BUI) and the Fire Weather Index (FWI), which are fire behavior indices whose values rise as the fire danger increases. They represent, respectively, the rate of fire spread, the fuel available for combustion and the frontal fire intensity. FWI components are estimated with daily values at 18 UTC of air temperature, air relative humidity, wind speed, and previous 24-hour precipitation. Meteorological data from the European Centre for Medium-Range Weather Forecasts' (ECMWF) ERA5 reanalysis product (C3S, 2017) were employed.

In this study, we use the Daily Severity Rating (DSR), an extension of the FWI system, consisting of a numeric rating that indicates the difficulty to control fires, more accurately reflecting the expected efforts required for fire suppression. Computation of DSR requires applying a power relation emphasizing higher FWI values. Silva et al. (2019) showed that $71 \%$ of the interannual variability of SBA in Cerrado can be explained using the DSR.

\subsection{Statistical analysis}

Accumulated monthly SBA values were estimated for each microregion to evaluate the trends of interannual SBA and drivers over the 2001-2018 period. As proposed in previous works (Rodrigues et al., 2019; Nogueira et al., 2017) we analyzed SBA in Cerrado's dry season: June, July, August, September, and October (JJASO), when there is highest fire incidence in this biome.

Relationships between interannual SBA and anthropogenic drivers were evaluated through the determination coefficient and corresponding $\mathrm{p}$-value from simple linear regression.

For the trend analysis, we used the non-parametric Theil-Sen regression (Theil, 1950; Sen, 1968), a robust estimator insensitive to outliers with a breakdown point of about $29.3 \%$ in regards to that of simple linear regression. The statistical significance of the trends was evaluated by the two-tailed MannKendall non-parametric test (Mann, 1945; Kendall, 1975). The test assumes that when no trend is present, the observations are not serially correlated over time. Hence, we detrended each time series by subtracting its corresponding Theil-Sen regression equation and evaluated for autocorrelation between ranks (Hamed, Rao, 1998). The modified Mann-Kendall test accounts for the effects of serial correlation in data and was applied to the detrended time series that showed to be serially correlated.

\section{RESULTS AND DISCUSSION}

\subsection{Temporal and spatial distribution of SBA}

Over the last 18 years, MATOPIBA accounted for approximately $58 \%$ of burned area in the Cerrado biome (Figure 2), a significant amount considering that MATOPIBA accounts for $35 \%$ of this biome's area. Its contribution is relatively constant: around half 
of Cerrado's total SBA. The SBA in MATOPIBA was lowest at the beginning of the century ( $53 \%)$ compared to that of the last few years $(\sim 61 \%)$, hinting at increased importance in Cerrado's total burned area.

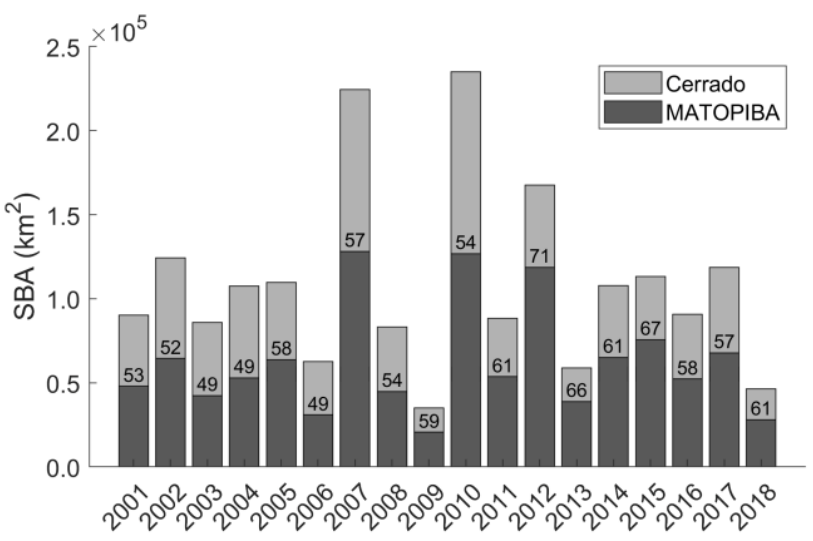

Figure 2. Burned area $\left(\mathrm{km}^{2}\right)$ in MATOPIBA (dark grey) and Cerrado (light grey) for the dry season from 2001 to 2018. Numbers above dark grey bars reflect the percentage of burned area in MATOPIBA in regards to that of Cerrado's in each year.

The highest contribution $(\sim 71 \%)$ of MATOPIBA to the total burned area in Cerrado was observed in 2012, whereas the lowest ( 49\%) were in the years 2003, 2004 and 2006 (Figure 2). Its highest SBA values are in the years 2007, 2010 and 2012, coinciding with those of Cerrado. These were years of drought events in Brazil: the dry season months of 2007 saw anomalous precipitation values, below the average for Cerrado (Mataveli et al., 2018); a similar case was found for 2010 (Mataveli et al., 2018; Marengo et al., 2017), a year also known for a widespread drought in the Amazon rainforest (Marengo et al., 2011); lastly, northeast Brazil was also found to be in severe drought in 2012 (Marengo et al., 2013). Drought-fire interactions are often associated with major fire activity events (Brando et al. 2014), and several studies have pinpointed the inverse relationship between burned area and precipitation in Cerrado (Nogueira et al., 2017; Libonati et al., 2015), where seasonal fire activity increases with a rapid drying of fuel.

The highest SBA counts are represented by microregions localized in the Tocantins (TO) state, accounting for, on average, $50 \%$ of MATOPIBA's total burned area over the 18 years. The remaining microregions in the other states account for approximately $23 \%$ (MA), $13 \%$ (PI) and $14 \%$ (BA) of total burned area in MATOPIBA. There are six microregions that burned more than twice its area over the 18 years, all within the 15 largest microregions of MATOPIBA (with over $20000 \mathrm{~km}^{2}$ ). Of these, only Alto Parnaíba Piauiense/PI(3) is not located in TO or MA. Jalapão/TO(27) achieved the highest SBA value, burning more than thrice its area $(332 \%)$ over the study period, a concerning figure, given that it is the largest microregion in MATOPIBA (with $53507 \mathrm{~km}^{2}$ ).

\subsection{Drivers of spatial burned area patterns}

To assess the influence of CL and LU in spatial SBA trends, we evaluated coefficients of determination derived from simple linear regression (Figure 3). The linear relationship of SBA and $\mathrm{CL}$ is that of positive slope for all microregions, meaning that when CL increases, SBA increases as well. CL significantly explains on average $52 \%$ of MATOPIBA's interannual variance (p-value below 0.001 ) and more than $25 \%$ in most microregions
(25 out of 41). Furthermore, CL explains at least half the interannual variance in six microregions and, of these, only Rio Formoso/TO(37) is amongst those with the highest burned area. The remaining five microregions with the highest burned area values, identified in the previous section, have coefficients of determination in the range $6-22 \%$, suggesting that climate is not the main driver in these microregions but rather an aggravating factor.
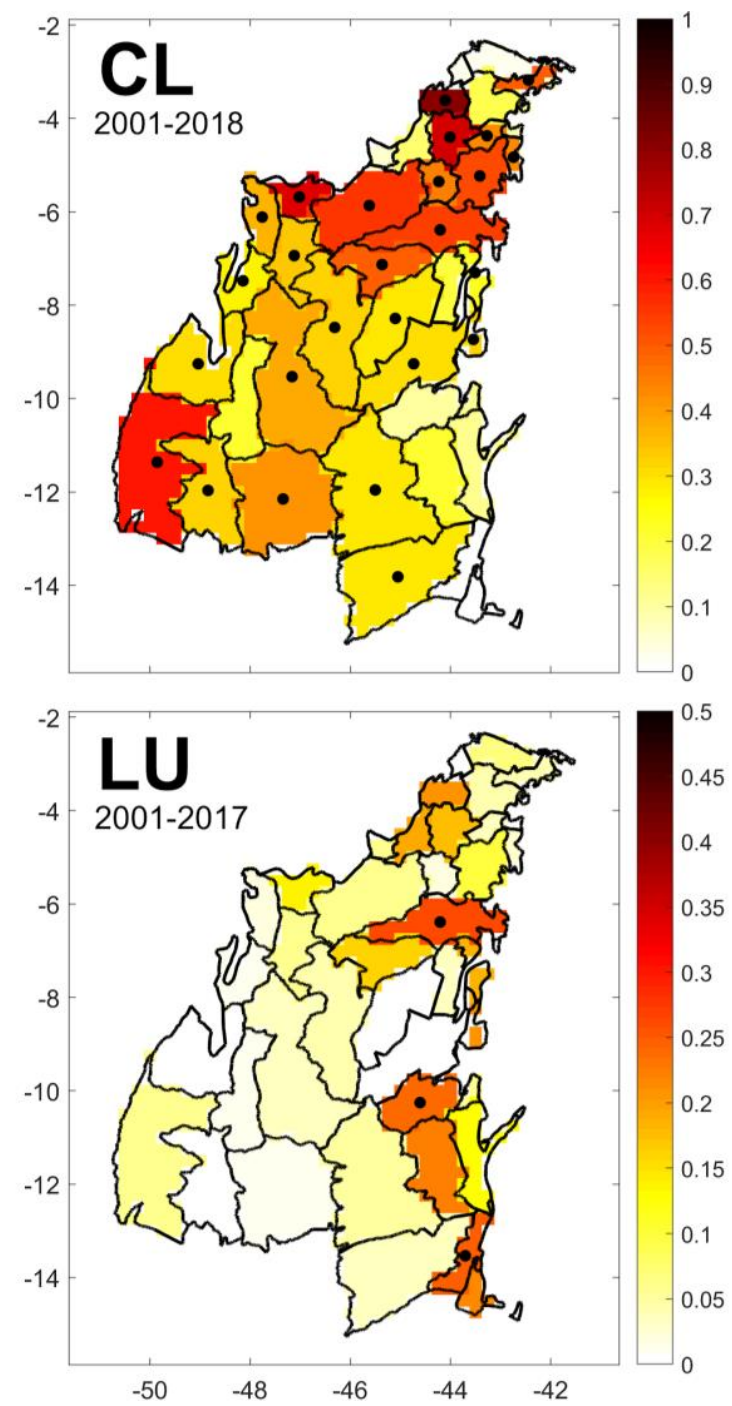

Figure 3. Coefficient of determination values between SBA and CL/LU (upper/lower figure) for MATOPIBA from 2001 to $2018 / 2017$, respectively. Values close to $1(0)$ indicate a high (low) relation between SBA and CL/LU. The filled (empty) circles represent significance below the $5(10) \%$ level.

Microregions presenting higher correlation with CL are mostly located in the northern region of MATOPIBA, where the larger areas of native vegetation (savanna) are located and might have not yet been disrupted by anthropogenic activity. Low values obtained for the coefficients of determination might suggest that MATOPIBA is shifting from a climate-controlled historical fire season to a disturbed regime.

On the other hand, SBA and LU present different relationships depending on microregion, resulting in an overall non-significant low coefficient of determination for MATOPIBA (1.4\% with a $\mathrm{p}$-value of 0.65). The relationship between SBA and LU is much 
more complex than that of SBA and CL, as it is highly dependable on the type of land use change. The use of fire to expand the agricultural frontier has been characterized by two stages: the use of fire to clear native vegetation into arable land, in which case burned area increases; and the use of controlled and seasonal fire in the harvest season and to clear the agricultural fields, in which case burned area decreases. Accordingly, when performing simple linear regression using $\mathrm{LU}$ as a predictor of burned area, distinct signals were found. All microregions in BA obtained a negative slope, indicating an inverse relationship: the higher the land use, the lower the SBA; which is in accordance with BA being a heavily deforested state with most of its area used for agriculture. Oppositely, microregions in MA presented mostly positive slopes, confirming the clearing of native vegetation discussed previously, and subsequent higher burned areas. However, the vast majority of these relationships are not significant at the $5 / 10 \%$ level. LU only explains more than $25 \%$ of the variance in two microregions, significantly at the 5\% level: Bom Jesus da Lapa/BA(11) and Chapadas do Alto Itapecuru/MA(14). Chapadas do Extremo Sul Piauiense/PI(15) closely follows with $\mathrm{R}^{2}=0.24$, equally significant at the $5 \%$ level. Moreover, when looking at Chapadas do Alto Itapecuru/MA(14), CL explains 54\% and LU explains 27\%, suggesting that this region is heavily influenced by these two drivers.

The remaining of MATOPIBA, although substantially influenced by $\mathrm{CL}$ and, in the case of some microregions, LU as well, might be also constrained to other drivers not studied here. We hypothesize that population density, urban area, fuel availability and topography might play a significant role in SBA variability as well as fire management and environmental policies.

\subsection{Trends of spatial burned area patterns}

Opposite SBA trends are found within MATOPIBA (Figure 4, top figure): MA presents an overall significant positive trend, whereas BA shows a negative trend; the remaining states (TO and PI) show contrasting patterns within their borders. Consequently, when analyzing SBA trends for the entirety of the MATOPIBA no conclusion can be drawn, which is not the case for both the CL and LU drivers (Figure 4, middle and bottom figures) that present significant positive trends in the region below the 5\% significance level.

When evaluating at the state level the only state presenting a significant SBA trend was MA, with a positive trend over the last 18 years (p-value of 0.003 ). Accordingly, significant positive SBA trends are found within central MA, consistent with significant positive LU trends: amongst the four states, Maranhão presents the highest amount of Cerrado's native vegetation and it has been increasingly cleared over the study period for agricultural purposes. Southern MA and western PI show predominantly non-significant positive trends, which is consistent with increased agricultural expansion over the study period (Bolfe et al., 2017)

Northwestern TO, limiting the Cerrado and Amazon biomes, presents predominantly negative SBA trends and significant positive LU trends. This region is part of the Arc of Deforestation, an area characterized by historical deforestation and, accordingly, these microregions were, at the beginning of our study period, mostly deforested. Although our results show a continued agricultural expansion over the 2001-2018 period, fire activity in these microregions is controlled and used mainly for agricultural practices, consistent with the negative trends of SBA.
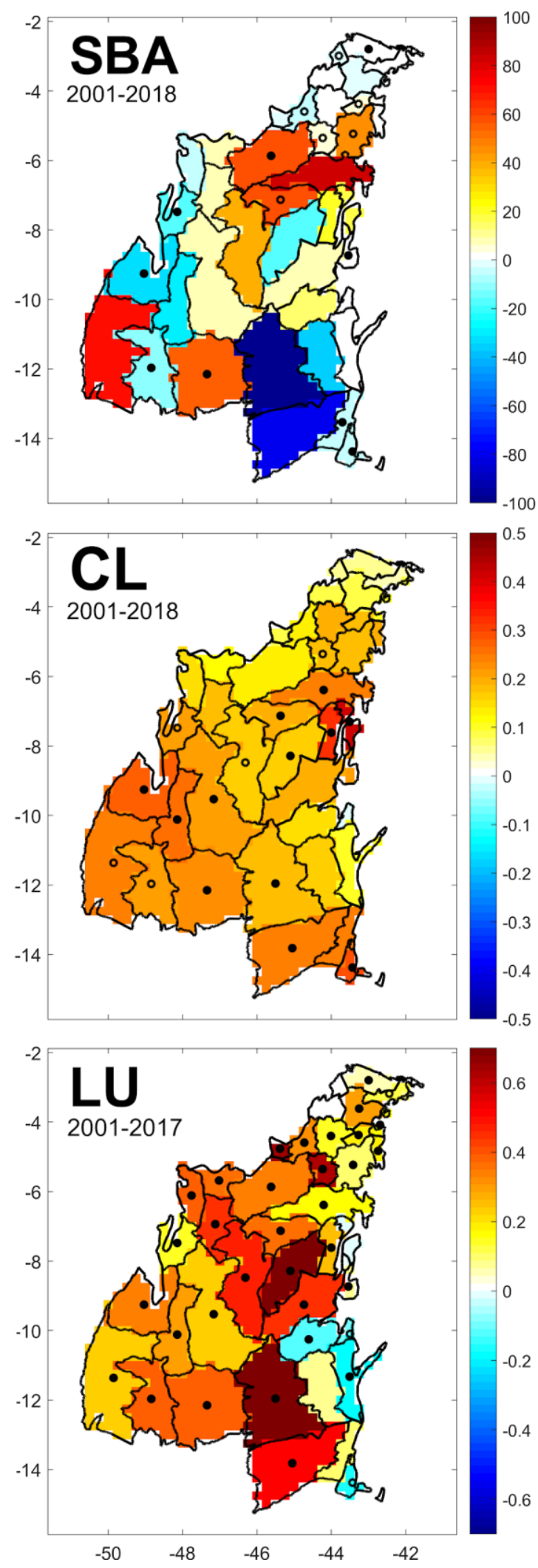

Figure 4. Trends of SBA, CL and LU for the study region over 2001-2018. Warmer (cooler) colors represent an upward

(downward) trend and filled (empty) circles represent significance below the $5(10) \%$ level.

Although mostly not statistically significant, BA shows decreasing SBA trends. This region has also seen substantial 
agricultural expansion over the last few years: data from GITE EMBRAPA shows that Barreiras/BA(8) and Santa Maria da Vitoria/BA(39) were amongst the microregions with the highest production of cotton, corn and soy in 2012 (Pereira, Pauli, 2016). However, when looking at LU trends, significant negative trends are found in eastern BA microregions. These microregions are in the transition between the Cerrado and Caatinga biomes, the latter is a semiarid ecosystem characterized by a long dry season. Given its longer period without rain, along with disadvantageous topography, the expansion of agricultural land use in Caatinga is difficult (Mingoti et al., 2014). It's worth noting that these microregions in BA showing significant decreasing trends, along with Chapadas do Extremo Sul Piauiense/PI(15), show minor variations along the 18 years of data (decreases of the normalized burned area around $0.1-1.4 \%$ ). Moreover, excluding Guanambi/BA(23), they do not have high LU percentages (average over the 17 years: range 3-14\%).

Overall, microregions that present significant LU positive trends above 0.45 are amongst those with the highest deforestation rates (Garcia, Vieira Filho, 2018) but also those with highest growth and concentration of annual cropland area in this century (Lorensini et al., 2015), that have been previously subject to human-driven change.

Lastly, CL presents positive trends for all microregions, some of them significant at the $5 / 10 \%$ level (17 out of 41$)$. This indicates fire danger (and thus climate conditions favorable for fire activity) has been increasing over the last 18 years. This is in agreement with the analysis of increased temperature and decreased precipitation and moisture over the last decades for Brazil (de Barros Soares et al., 2017). Furthermore, when looking at historical data from 1989 onwards these trends not only obtain higher absolute values, as all microregions in MATOPIBA present significant values below the 5\% level, except for northern MA. A positive CL trend reflects changes in meteorological parameters (namely increased temperature and lower relative humidity) that might have profound effects on the seasonality of fire activity and vegetation phenology. This takes special relevance in light of future projections for the Brazilian Cerrado that show increased fire danger under several climate change scenarios for the $21^{\text {st }}$ century (Silva et al., 2019), suggesting that this historical positive CL trend over Cerrado will most likely be kept.

\section{CONCLUSIONS}

MATOPIBA's importance in the context of fire activity in Cerrado is not to be disregarded as we found that this region represents more than half the annual burned area of the Brazilian savanna. Maranhão and Tocantins states have the highest contributions to this value, contributing to $73 \%$ of MATOPIBA's total burned area over 2001-2018. Burned area totals also showed that some microregions burned more than twice its area over the study period.

SBA was found to be significantly constrained by climate and we hypothesize that anthropogenic drivers (including those not evaluated in this work, such as urban areas, deforestation, fuel availability, fire management, environmental policies and population density) play a substantial role in short term SBA trends. It's worth emphasizing that climate provides conditions for burning, but fire events are always dependent on ignition, which in Brazil is known to be almost certainly human. Land use did not prove to be a relevant factor in the vast majority of MATOPIBA, which leads us to conclude that the human-driven component of burned area must be further evaluated. This driver was also found to be very complex to analyze its influence on burned area given the high dependence on the regional context.

Overall trends in MATOPIBA of CL and LU have been of increase over the 2001-2018 period; SBA, however, presented very distinct trends within the study region. Although constrained to administrative areas, this study provides useful information to characterize each microregion and contribute for improved and more adequate policy measures.

\section{ACKNOWLEDGEMENTS}

The study was funded by CNPQ (grant 441971/2018-0) and P. Silva is supported by FCT (grant SFRH/BD/146646/2019).

\section{REFERENCES}

Bolfe, E. L., Victoria, D. C., Contini, E., Bayma-Silva, G., Spinelli-Araujo, L., Gomes, D., 2017. MATOPIBA: análise do uso da terra e a produção agrícola. In: XVIII Simpósio Brasileiro de Sensoriamento Remoto-SBSR, Santos, Brazil.

Brando, P.M., Balch, J.K., Nepstad, D.C., Morton, D.C., Putz, F.E., Coe, M.T., Silvério, D., Macedo, M.N., Davidson, E.A., Nóbrega, C.C., Alencar, A., Soares-Filho, B.S., 2014. Abrupt increases in Amazonian tree mortality due to drought-fire interactions. Proceedings of the National Academy of Sciences of the United States of America, 111(17), 6347-6352.

Copernicus Climate Change Service (C3S), 2017. ERA5: Fifth generation of ECMWF atmospheric reanalyses of the global climate. Copernicus Climate Change Service Climate Data Store (CDS). https://cds.climate.copernicus.eu (1 November 2019).

de Barros Soares, D., Lee, H., Loikith, P. C., Barkhordarian, A., Mechoso, C. R., 2017. Can significant trends be detected in surface air temperature and precipitation over South America in recent decades? International Journal of Climatology, 37(3), 1483-1493.

Durigan, G., Ratter, J. A., 2016. The need for a consistent fire policy for Cerrado conservation. Journal of Applied Ecology, 53(1), 11-15.

Dwyer J., Schmidt G., 2006: The MODIS Reprojection Tool. In: Qu J.J., Gao W., Kafatos M., Murphy R.E., Salomonson V.V. (eds) Earth Science Satellite Remote Sensing. Springer, Berlin, Heidelberg.

Garcia, J. R., Vieira Filho, J. E. R., 2018. O papel da dimensão ambiental na ocupação do MATOPIBA. Confins: revista francobrasileira de geografia, 35.

Giglio, L., Boschetti, L., Roy, D. P., Humber, M. L., Justice, C. O., 2018. The Collection 6 MODIS burned area mapping algorithm and product. Remote Sensing of Environment, 217, 7285

Hamed, K. H., Rao, A. R., 1998. A modified Mann-Kendall trend test for autocorrelated data. Journal of Hydrology, 204(1-4), $182-196$.

Hardesty, J., Myers, R., Fulks, W., 2005. Fire, ecosystems and people: a preliminary assessment of fire as a global conservation issue. Fire Management, 22(4), 78-87. 
Hoffmann, W. A., Jaconis, S. Y., Mckinley, K. L., Geiger, E. L., Gotsch, S. G., Franco, A. C., 2012. Fuels or microclimate? Understanding the drivers of fire feedbacks at savanna-forest boundaries. Austral Ecology, 37(6), 634-643.

Instituto Brasileiro de Geografia e Estatística (IBGE), 1990. Divisão do Brasil em mesorregiões e microrregiões geográficas. v.1. Rio de Janeiro, ISBN 2408456300.

Kendall, M. G., 1975: Rank correlation Methods. 4.ed. Londres: Charles Griffin.

Lapola, D. M., Martinelli, L. A., Peres, C. A., Ometto, J. P. H. B., Ferreira, M. E., Nobre, C. A., Aguiar, A. P. D., Bustamante, M. M. C., Cardoso, M. F., Costa, M. H., Joly, C. A., Leite, C. C., Moutinho, P., Sampaio, G., Strassburg, B. B. N., Vieira, I. C. G., 2014. Pervasive transition of the Brazilian land-use system. Nature Climate Change, 4(1), 27-35.

Libonati, R., DaCamara, C., Setzer, A., Morelli, F., Melchiori, A., 2015. An Algorithm for Burned Area Detection in the Brazilian Cerrado Using $4 \mu \mathrm{m}$ MODIS Imagery. Remote Sensing, 7(11), 15782-15803.

Lorensini, C. L., Victoria, D. C., Vicente, L. E., Maçorano, R. P., 2015. Mapeamento e identificação da época de desmatamento das áreas de expansão da agricultura no MATOPIBA. In: XVII Simpósio Brasileiro de Sensoriamento Remoto-SBSR, Santos, Brazil.

Mann, H. B., 1945. Nonparametric Tests Against Trend. Econometrica, 13(3), 245.

MapBiomas Project, 2019. Collection 3.1 of Brazil's Annual Land cover and Land Use Mapping. https://mapbiomas.org (1 November 2019).

Marengo, J.A., Tomasella, J., Alves, L.M., Soares, W.R., Rodriguez, D.A., 2011. The drought of 2010 in the context of historical droughts in the Amazon region. Geophysical Research Letters, 38 .

Marengo, J. A., Alves, L. M., Soares, W. R., Rodriguez, D. A., Camargo, H., Paredes, M., Diaz Pablo, A., 2013. Two contrasting seasonal extremes in tropical South America in 2012: flood in Amazonia and drought in Northeast Brazil. Journal of Climate, 26(22), 9137-9154.

Marengo, J. A., Torres, R. R., Alves, L. M., 2017. Drought in Northeast Brazil-past, present, and future. Theoretical and Applied Climatology, 129(3-4), 1189-1200.

Mataveli, G.A.V., Silva, M.E.S., Pereira, G., Da Silva Cardozo, F., Shinji Kawakubo, F., Bertani, G., Cezar Costa, J., De Cássia Ramos, R., Da Silva, V.V., 2018. Satellite observations for describing fire patterns and climate-related fire drivers in the Brazilian savannas. Natural Hazards and Earth System Sciences, $18,125-144$.

Mingoti, R., Brasco, M. A., Holler, W. A., Lovisi Filho, E., Spadotto, C. A., 2014. Matopiba: caracterização das áreas com grande produção de culturas anuais. Technical Note EMBRAPA. https://www.alice.cnptia.embrapa.br/handle/doc/991059 November 2019).

Miranda, E. E. de, Magalhães, L. A., Carvalho, C. A. de. Proposta de delimitação territorial do MATOPIBA. Nota Técnica 1, GITE
- Grupo de Inteligência Territorial Estratégica, Embrapa, Campinas, SP, maio/2014. https://goo.gl/vBROXd (27 July 2016).

Nogueira, J., Rambal, S., Barbosa, J., Mouillot, F., 2017. Spatial Pattern of the Seasonal Drought/Burned Area Relationship across Brazilian Biomes: Sensitivity to Drought Metrics and Global Remote-Sensing Fire Products. Climate, 5(2), 42.

Pereira, L. I., Pauli, L., 2016. O processo de estrangeirização da terra e expansão do agronegócio na região do MATOPIBA. CAMPO-TERRITÓRIO: revista de geografia agrária, Special Edition, 196-224.

Pinto, M. M., DaCamara, C. C., Trigo, I. F., Trigo, R. M., Turkman, K. F., 2018. Fire danger rating over Mediterranean Europe based on fire radiative power derived from Meteosat. Natural Hazards and Earth System Sciences, 18(2), 515-529.

Rodrigues, J. A., Libonati, R., Pereira, A. A., Nogueira, J. M. P., Santos, F. L. M., Peres, L. F., Rosa, A. S., Schroeder, W., Pereira, J. M. C., Giglio, L., Trigo, I. F., Setzer, A.W., 2019. How well do global burned area products represent fire patterns in the Brazilian Savannas biome? An accuracy assessment of the MCD64 collections. International Journal of Applied Earth Observation and Geoinformation, 78, 318-331.

Sano, E. E., Rosa, R., Brito, J. L. S., Ferreira, L. G., 2010. Land cover mapping of the tropical savanna region in Brazil. Environmental Monitoring and Assessment, 166, 113-124.

Sen, P. K., 1968. Estimates of the Regression Coefficient Based on Kendall's Tau. Journal of the American Statistical Association, 63(324), 1379-1389.

Silva, P. S., Bastos, A., Libonati, R., Rodrigues, J. A., DaCamara, C. C., 2019. Impacts of the $1.5^{\circ} \mathrm{C}$ global warming target on future burned area in the Brazilian Cerrado. Forest Ecology and Management, 446, 193-203.

Song, X. P., Hansen, M. C., Stehman, S. V., Potapov, P. V., Tyukavina, A., Vermote, E. F., Townshend, J. R., 2018. Global land change from 1982 to 2016. Nature, 560(7720), 639-643.

Taylor, S. W., Alexander, M. E., 2006. Science, technology, and human factors in fire danger rating: the Canadian experience. International Journal of Wildland Fire, 15(1), 121.

Theil, H., 1950. A rank-invariant method of linear and polynomial regression analysis. Indagationes Mathematicae, $1(2), 467-482$.

Van Wagner, C.E., 1987. Development and structure of the Canadian Forest Fire Weather Index System. Canadian Forestry Service. 